\title{
DO MODERNISMO AO ALGORITMO: EVOLUÇÃO E PERSPECTIVAS DA POLÍTICA PATRIMONIAL BRASILEIRA
}

\author{
FROM MODERNISM TO ALGORITHM: EVOLUTION AND PERSPECTIVES OF BRAZILIAN CULTURAL HERITAGE POLICY
}

\section{RESUMO}

Cultura é um termo de acepção ampla e, salvo se restrito em sua dimensão espacial e temporal, possui uma polissemia que dificulta sobremaneira sua conceituação. Daí porque, para entender a política pública de proteção do patrimônio cultural nas duas décadas do século XXI e as perspectivas futuras, é pertinente fazer uma investigação dos atores e premissas teóricas envolvidas na seleção dos bens materiais e imateriais a serem acautelados. Esse é o objetivo do presente artigo. Para alcança-lo, inicialmente se analisou a influência do pensamento modernista nas três primeiras décadas desde seu surgimento (1937-1967). Nessa chamada fase heroica, prevalecia a concepção dessa elite intelectual daquilo que deveria representar simbolicamente a cultura nacional. Em seguida, a aproximação do patrimônio cultural com o desenvolvimento econômico alterou significativamente os parâmetros de valoração e gestão. Diversos planos de financiamento se imbricaram diretamente com os critérios teóricos de seleção, influenciando-os e sendo influenciados numa complexa dinâmica de pensamento e ação. Nesse contexto, concluiu-se que uma das marcas da política pública patrimonial nas duas décadas do século XXI foi a relativa descentralização político-administrativa de sua execução, mesmo que com revezes. Por fim, propôs-se em perspectiva uma potencial migração desse protagonismo estatal - centralizado ou descentralizado - para as grandes empresas de tecnologia, em especial com a difusão da cultura dos algoritmos.

Palavras-chave: Patrimônio cultural. Política pública. Modernismo. Desenvolvimento econômico. Algoritmo.

\section{ABSTRACT}

Culture is a broad term that, unless restricted in its spatial and temporal dimension, has a polysemy that hinders its conceptualization. That is why, to understand the public policy of cultural heritage protection in the first two decades of the 21st century and its perspectives, it is pertinent to make an investigation of the actors and theoretical premises involved in the selection of material and immaterial goods to be safeguarded. This is the purpose of this article. To achieve this, the influence of modernist thought was initially analyzed in the first three decades since its inception (1937-1967). In this so-called heroic phase, the intellectual elite's conception of what should symbolically represent national culture prevailed. Then, the approximation of cultural heritage with economic development significantly changed the valuation and management parameters. Several funding plans have directly intertwined with the theoretical selection criteria, influencing them and being influenced by a complex dynamic of thought and action. In this context, it was concluded that one of the hallmarks of patrimonial public policy in the two decades of the 21st century was the relative political-administrative decentralization of its execution, albeit with setbacks. Finally, a potential migration from this centralized or decentralized state role to large technology companies was proposed in perspective, especially with the diffusion of the culture of algorithms.

Keywords: Cultural heritage. Public policy. Modernism. Economic development. Algorithm.

\section{Dhiago Serpa Erthal a, b}

a Universidade do Estado do Rio de Janeiro (UERJ), Rio de Janeiro, RJ, Brasil

${ }^{\text {b }}$ Advocacia-Geral da União (AGU), Rio de Janeiro, RJ, Brasil

DOI: 10.12957/geouerj.2020.48419

Correpondência: thiagoerthal@yahoo.com.br

Recebido em: 20 set. 2019

Revisado em: 19 out. 2019

Aceito em: 22 dez.2019 


\section{INTRODUÇÃO}

Cultura é um termo de acepção ampla e, salvo se restrito em sua dimensão espacial e temporal, possui uma polissemia que dificulta sobremaneira sua conceituação e, por consequência, também a noção de política pública voltada para sua regulação e fomento. Afinal, como é possível pensar a atuação do Poder Público para consecução de determinada finalidade se o próprio objetivo a ser alcançado não pode ser claramente definido?

Em âmbito jurídico, opta-se em regra pela reprodução quase indiscriminada de alguns dispositivos legais ou pela aceitação de uma concepção intuitiva do que a palavra constitui, mas existe também esforço pelo rigor científico nessa definição. Em recente obra sobre direitos culturais, Cunha $(2018$, p.19) aponta seis grandes núcleos de significados correntes atribuídos ao termo.

Em suma e segundo o autor, cultura pode se reportar ao conjunto de conhecimentos de uma única pessoa; confundir-se com expressões como arte, artesanato ou folclore; conceber-se como um conjunto de crenças, ritos, mitologias e demais aspectos imateriais de um povo; direcionar para o desenvolvimento e acesso às modernas tecnologias; distinguir conjuntos de saberes, modos e costumes de uma classe, categoria ou ciência; ou se reportar a toda e qualquer produção material e imaterial de uma pessoa ou coletividade.

Para longe de se pretender afirmar peremptoriamente um conceito único e absoluto de cultura, é o reconhecimento dessa polissemia que mais interessa. Nessa esteira, a diversidade de significados permite ao Poder Público - mais especificamente ao Estado-executor - mudar diametralmente as diretrizes básicas dessa política sem qualquer alteração textual nas normas jurídicas que lhe dão substrato.

Ao fazê-lo, o Estado está - consciente ou inconscientemente, implícita ou explicitamente - impondo a sua visão daquilo que entende por cultura, o seu conceito próprio. E uma perspectiva histórica desse fenômeno ajuda a compreender não só o processo de formação dessa política pública, como principalmente as diretrizes atuais e suas perspectivas futuras.

No entanto, uma restrição de objeto se faz necessária. Ainda que essa afirmação valha para a política pública cultural como um todo, propõe-se aqui análise delimitada a um setor em específico: à política de proteção do patrimônio cultural urbano, é dizer, ao resguardo de bens de natureza corpórea ou incorpórea selecionados para representar simbolicamente a cultura nacional.

Para tanto, o artigo será dividido em quatro capítulos cronologicamente encadeados, ainda que com certa sobreposição temporal entre eles. No primeiro, abordar-se-á o surgimento da política pública em 1937 e as premissas teóricas e administrativas que lhe orientaram durante a chamada fase heroica, até 1967. Em 
seguida, será examinado o processo de aproximação do patrimônio cultural às propostas de desenvolvimento econômico, marca da segunda metade do século XX.

Finalmente, os dois capítulos seguintes corresponderão respectivamente a um exame da política pública patrimonial nas duas décadas do século XXI e a formulação de algumas perspectivas de como as novas tecnologias podem influenciar a atividade estatal nessa seara em especial.

A cultura da União: surgimento da política patrimonial à luz do modernismo

Em âmbito interno, a política pública de proteção do patrimônio cultural - doravante política patrimonial - começou a ser gestada no final da década de 1920 e início da década de 30 a partir de um grupo de intelectuais brasileiros representantes do movimento modernista. Na época, crescia a noção de que o Brasil precisava construir (ou descobrir) sua nacionalidade a partir de um patrimônio histórico e artístico representativo de sua grandeza.

Modernismo e política patrimonial, portanto, estão intrinsecamente ligados, tanto no que se refere à construção dessa atividade estatal quanto às premissas teóricas que lhe orientaram. Nesse sentido, a conjunção desse movimento intelectual com as circunstâncias político-administrativas viabilizou a criação, em 1936, na estrutura do então Ministério da Educação e Saúde (MES), do Serviço do Patrimônio Histórico e Artístico Nacional (SPHAN) ${ }^{1}$.

Para dirigir o órgão, foi nomeado Rodrigo Melo Franco de Andrade, advogado mineiro, que ficaria à frente dessa função nas três décadas seguintes, até sua aposentadoria em 1967, período que mais tarde ficaria conhecido como fase heroica. Para auxiliá-lo nessa atividade, Rodrigo M. F. de Andrade trouxe para o SPHAN outros intelectuais modernistas, como Mario de Andrade, Lucio Costa e Carlos Drummond de Andrade.

Nesse contexto e apenas 20 dias depois de instaurado o Estado Novo, foi publicado o Decreto-lei no 25, de 30 de novembro de 1937, que marca formal e normativamente o início da política patrimonial brasileira. Já em seu art. 1으, o DL no 25/37 evidencia sua íntima relação com os ideais modernistas, ao dispor que o patrimônio histórico e artístico nacional se constituiria pelo conjunto de bens móveis e imóveis cuja conservação fosse de interesse público, quer por sua vinculação a fatos memoráveis da história do Brasil, quer por seu excepcional valor arqueológico, etnográfico, bibliográfico ou artístico.

Tal diploma criou quatro categorias, dentro das quais o bem selecionado deveria se enquadrar, cada uma delas associada a um livro de tombo: (i) arqueológico, etnográfico e paisagístico; (ii) histórico; (iii) das Belas Artes; e (iv) das Artes Aplicadas. Além dessa rígida categorização, a criação de signos da cultura nacional

${ }^{1}$ O SPHAN foi formalmente incorporado à estrutura do MES através da Lei no 378, de 13 de janeiro de 1937. 
pressupunha uma monumentalidade do bem acautelado ${ }^{2}$, sua vinculação a fatos memoráveis ou excepcional valor arqueológico ou etnográfico, bibliográfico ou artístico.

O que não estava escrito no DL no 25/1937 mas marcou essas três primeiras décadas de política pública foi a absoluta preferência dada à arte erudita, notadamente à arquitetura de pedra-e-cal, que resultou na sobrevalorização do livro de tombo das belas artes em detrimento dos demais ${ }^{3}$.

No célebre estudo sobre a Capela de Santo Antônio, no Município de São Roque, Mário de Andrade (1937, p.120-121) demonstra expressamente sua posição:

\begin{abstract}
O critério para um trabalho proveitoso de defesa e tombamento do que o passado nos legou tem de se pautar, no Estado de São Paulo, quase exclusivamente pelo ângulo histórico. [...] Se é certo que uma pesquisa muito paciente pode encontrar detalhes de beleza ou soluções de interesse técnico, num teto ou torre sineira, num alpendre ou numa janela gradeada, é mais incontestável ainda, a meu ver, que São Paulo não pode apresentar documentação alguma que, como arte, se aproxime sequer da estatuária mineira, da pintura, dos entalhes e dos interiores completos do Rio, de Pernambuco ou da Bahia.

O critério tem de ser outro. Tem de ser histórico, e em vez de se preocupar muito com beleza, há de reverenciar e defender especialmente as capelinhas toscas, as velhices dum tempo de luta e os restos de luxo esburacado que o acaso se esqueceu de destruir.
\end{abstract}

Essa preferência por um determinado tipo de arquitetura - e, afinal, uma noção própria de patrimônio cultural - reflete-se ainda hoje na quantidade de bens inscritos por Estado. Com efeito, enquanto Minas Gerais e São Paulo têm praticamente o mesmo número de inscrições no livro de tombo histórico (respectivamente 76 e 77), no das belas artes esse número é quase três vezes maior (172 em MG contra 60 em SP).

No que tange ao tombamento de núcleos urbanos, essa preferência é ainda mais proeminente. Com efeito, Marcia Sant'Anna (2014, p.169-177) explica que até o final da década de 1960, as cidades-monumento eram consideradas como obras de arte acabadas, que deveriam ser preservadas em seu status quo. Não por outro motivo, o SPHAN tombava tão-somente pequenas cidades mineiras de arquitetura colonial (Ouro Preto, Mariana, Diamantina etc) ou fragmentos urbanos das cidades maiores, para que permanecessem intocados e em regra excluídos da dinâmica urbana.

Analisando esse período histórico, Maria Cecília Londres Fonseca (2017, p.114) observa que os critérios de seleção, autenticação e restauração dos bens que passaram a compor o patrimônio histórico e artístico nacional eram sustentados basicamente na autoridade e notório saber dos integrantes do SPHAN. Por

\footnotetext{
${ }^{2}$ Apesar de já haver referências na época, em especial feitas por Mario de Andrade, o patrimônio cultural imaterial só veio a ser institucionalmente acautelado com a edição do Decreto no 3.551, de 04 de agosto de 2000.

3 Por exemplo, das 1.699 inscrições que constam atualmente na lista de bens tombados, apenas quatro são do livro de artes aplicadas. Disponível em:

<http://portal.iphan.gov.br/uploads/ckfinder/arquivos/BENS\%20TOMBADOS\%20E\%2OPROCESSOS\%20EM\%20ANDAMENTO\%202019 \%20MAIO.pdf>. Acesso em: 02 set. 2019.
} 
consequência, durante toda a fase heroica, prevaleceu a visão modernista do que significava cultura e, mais especificamente, de quais bens seriam dignos de proteção direta ou indireta pelo Poder Público.

A União, portanto, manteve por pelo menos três décadas o monopólio dessa política pública, de sua concepção à execução, ainda que a Constituição Federal de 1937 já determinasse a competência material comum de todos os entes federativos ${ }^{4}$. E, como nessas três décadas o SPHAN foi dirigido pelo grupo de intelectuais modernistas do eixo RJ-SP-MG, essa foi a perspectiva teórica que orientou toda a fase heroica, até a aposentadoria de Rodrigo M. F. de Andrade em 1967.

A cultura dos estados: desenvolvimento econômico, turismo e comunidade

Com a aposentadoria de Rodrigo M. F. de Andrade, evidenciou-se a fragilidade institucional da DPHAN ${ }^{5}$ (FONSECA, 2017, p.150). Sua apregoada autonomia técnica, que de certa forma o havia deixado ao largo de disputas políticas nessas três décadas, mostrou-se fraca e associada ao carisma e trânsito político de seu até então único diretor.

Frente a desafio de se reinventar, o SPHAN recorreu à Organização das Nações Unidas para a Educação, a Ciência e a Cultura (UNESCO) para reformular suas premissas de atuação institucional. Em resposta, a UNESCO enviou ao Brasil o Inspetor Principal dos Monumentos Franceses Michel Parent, que em duas viagens percorreu praticamente todo o território nacional para elaborar seu diagnóstico e proposta (SANT'ANNA, 2014, p. 207).

Nesse momento histórico, o urbanismo como um todo vinha observando profundas mudanças de paradigma. Os ideais expostos por Henri Lefebvre (1968) começavam a ecoar no planejamento urbano. Para o sociólogo francês, o urbanismo moderno despolitizado era, em verdade, o resultado da atuação do capital sobre o espaço urbano, e não a consequência de um planejamento técnico e imparcial como se propunha.

Ao argumentar que essa concepção de urbanismo era uma estratégia de mercantilização da vida mediante produção e racionalização do espaço, rompeu com o pensamento então prevalecente e deu início a uma nova fase de identificação do fenômeno urbano. De acordo com esse novo paradigma, um dos pilares técnicos que orientou grande parte dos intelectuais urbanistas deveria ser combatido, e não mais absorvido e replicado. O fracionamento do espaço era visto por Lefebvre como uma forma de isolamento social da classe trabalhadora, desestimulando qualquer tipo de comportamento insurgente.

\footnotetext{
${ }^{4}$ CF/1937, Art. 134. Os monumentos históricos, artísticos e naturais, assim como as paisagens ou os locais particularmente dotados pela natureza, gozam da proteção e dos cuidados especiais da Nação, dos Estados e dos Municípios. Os atentados contra eles cometidos serão equiparados aos cometidos contra o patrimônio nacional.

5 Por meio do Decreto-lei no 8.534, de 02 de janeiro de 1946, o SPHAN foi transformado na Diretoria do Patrimônio Histórico e Artístico Nacional (DPHAN), mantendo suas atribuições junto ao MES.
} 
No âmbito específico da política patrimonial, essa superação teórica da atuação exclusivamente técnicoprofissional pode ser vista com a mudança dos critérios de seleção e preservação da Carta de Atenas pelos da Carta de Veneza, divulgada por ocasião do II Congresso Internacional de Arquitetos e Técnicos dos Monumentos Históricos, realizado em maio de 1964.

A partir da década de 1960, portanto, o patrimônio cultural já não era mais visto exclusivamente sob o ponto de vista da elite intelectual modernista. Premissas antes tidas como irrefutáveis passaram a ser objeto de discussão e superação ${ }^{6}$. Nessa conjuntura, o relatório apresentado pelo representante da UNESCO (PARENT, 1968) trouxe diversas propostas para a execução da política patrimonial brasileira

Parent observou a necessidade de compatibilização da proteção dos bens acautelados com o desenvolvimento econômico. Ao invés de isolar o monumento ${ }^{7}$, propunha-se sua conservação pelo uso sustentável, em associação com duas outras políticas públicas: de fomento ao turismo e de habitação. O seguinte trecho do relatório é eloquente (PARENT, 1968, p.160):

\begin{abstract}
Por um lado, existe um banco da Habitação, por outro um ministério de Obras Públicas e Transportes, mas não, propriamente falando, um ministério da Construção e do Urbanismo. A existência de projetos urbanísticos globais é raríssima. $\mathrm{E}$, nesse ponto, a descentralização das iniciativas se traduz em uma lentidão crescente. Sem dúvida, por ter sido ao mesmo tempo o país mais bem dotado do continente americano em arquitetura tradicional e que o próprio desequilíbrio de sua expansão tenha deixado subsistir amplos conjuntos dessa arquitetura antiga, o Brasil detém uma riqueza arquitetônica que é, no fundo, ainda mais útil do que decorativa, mas que ao mesmo tempo também está mais ameaçada hoje pela expansão do que se pertencesse a uma esfera da cultura separada da vida cotidiana, como as jazidas arqueológicas. Para essa arquitetura, o problema é de fácil solução: é uma questão de vontade, de cota do esforço nacional a consagrar ao passado e à cultura, é uma aposta em sua rentabilidade turística; o México está resolvendo de forma exemplar esse problema, e o Peru se prepara para tanto (não que esses dois países não possuam cidades de arte, mas o fenômeno é mais restrito e secundário no contexto).
\end{abstract}

Indicava-se, assim, que a política pública deveria ser executada em cooperação com outras setoriais (habitação e turismo), visando a uma compatibilização entre proteção do patrimônio cultural e o desenvolvimento econômico. Para a consecução desse objetivo, Parent $(1968$, p.163) propôs que a DPHAN atuasse junto com os governos dos estados para cumprir a tarefa preconizada, o que marca no espectro teórico ${ }^{8}$ a quebra do monopólio da União afirmado no capítulo anterior.

No âmbito prático, isso se deu - dentre outras medidas - com a instituição junto à Secretaria de Planejamento (SEPLAN) da Presidência da República do Programa Integrado de Reconstrução das Cidades Históricas (PCH). Com efeito, em 1970 e 71, dois encontros de Governadores - que culminaram,

\footnotetext{
6 Um exemplo disso é a inscrição no livro de tombo das belas artes dos prédios de arquitetura eclética construídos na Av. Rio Branco, no Centro do Rio de Janeiro. Na oportunidade, contestou-se a premissa de Lucio Costa de que essas construções representavam não um estilo próprio, mas tão-somente uma fase de transição para a arquitetura moderna.

${ }^{7}$ A própria concepção de monumentalidade já vinha sendo substituída pela ideia de referência cultural, conforme se verificaria mais tarde na redação do art. 216 da Constituição Federal de 1988.

${ }^{8}$ Ainda sob a perspectiva teórica, no mesmo período foram publicadas as Normas de Quito, que reforçam em âmbito internacional as premissas apontadas pelo relatório de Parent.
} 
respectivamente, nos Compromissos de Brasília e Salvador - já anunciavam a proposta de atuação dos estados na política pública patrimonial.

Nesse cenário, a partir de um grupo de trabalho interministerial, a Exposição de Motivos no 076-B, de 21 de maio de 1973, criou o PCH como um programa regional, que objetivava gerar renda para o nordeste brasileiro através do incremento da atividade turística e da conservação do patrimônio histórico nacional. Segundo Sant'anna (2014, p.217), o universo inicial do programa abrangia os Estados de Alagoas, Bahia, Ceará, Maranhão, Paraíba, Pernambuco, Piauí, Rio Grande do Norte e Sergipe e seus recursos foram destinados basicamente à execução de obras de restauração e infraestrutura turística.

Os recursos do PCH advinham em sua maioria do Fundo de Desenvolvimento de Programas Integrados (FDPI) e eram repassados pela SEPLAN sempre a fundo perdido ${ }^{9}$. Isso estimulou que os estados do Nordeste criassem estruturas administrativas que lhe permitissem propor e executar projetos de preservação do patrimônio cultural praticamente à revelia do Instituto do Patrimônio Histórico e Artístico Nacional (IPHAN) ${ }^{10}$, o que até então parecia improvável.

Nos três anos que se seguiram, o programa conseguiu criar, no nível estadual, toda uma estrutura governamental para a proteção do patrimônio cultural (SANT’ANNA, 2014, p.226), incluindo finalmente os estados na execução de uma política pública cuja competência já lhe era conferida há mais de 30 anos. Data desse período a criação de órgãos estaduais na Bahia ${ }^{11}$, Sergipe, Alagoas, Pernambuco, Paraíba, Rio Grande do Norte, Ceará, Piauí e Maranhão.

Em 02 de fevereiro de 1977, o PCH foi estendido também para o Espírito Santo, Minas Gerais e Rio de Janeiro. Mas a Exposição de Motivos no 024 não trouxe apenas a expansão territorial, alterou também a ênfase do programa do turismo para projetos que visassem à solução de problemas urbanos de uma maneira mais ampla. A Exposição de Motivos no 320, de 08/11/1979, marcou em definitivo essa mudança de paradigma.

A cultura dos municípios: a política patrimonial nas duas décadas do século XXI

Com a extinção dos fundos geridos pela SEPLAN, o PCH e o Centro Nacional de Referência Cultural $(\mathrm{CNRC})^{12}$ foram absorvidos pelo IPHAN, que se transformou na Secretaria do Patrimônio Histórico e Artístico Nacional (SPHAN). No mesmo ano de 1979, foi criada a Fundação Nacional pró-Memória (FNpM), pela Lei no 6.757, de 17 de dezembro, para funcionar como braço executivo da nova Secretaria.

\footnotetext{
${ }^{9}$ Cf. Portaria no 49, de 30/07/1973, que regulamentou o FDPI.

10 O Decreto no 66.967, de 27 de julho, transformou a DPHAN no IPHAN.

${ }^{11}$ Especificamente na Bahia, não se pode atribuir diretamente ao PCH a criação da Fundação do Patrimônio Artístico e Cultural da Bahia (FPAC), eis que concretizada em 1967.

12 Para mais informações acerca do CNRC, cf. FONSECA, Maria Cecília Londres. O Patrimônio em Processo: trajetória da política federal de preservação no Brasil. 4. ed. Rio de Janeiro: UFRJ, 2017, pp. 153-64.
} 
Com isso, houve um retrocesso na tendência de descentralização indicada no capítulo anterior, voltando o sistema SPHAN/pró-Memória a funcionar de maneira centralizada ante as demais políticas públicas setoriais. Essa reestruturação evidenciou uma divisão interna de grupos que disputavam o poder ou simplesmente trabalhavam uns contra os outros (SANT'ANNA, 2014, p.266).

Na década de 1980, a comunidade - e não mais o turismo - passou a ser o foco da atuação pública visando à preservação dos bens acautelados. Nessa esteira, logo no início da sua gestão, Aluísio Magalhães afirmou que a solução dos problemas de conservação do patrimônio arquitetônico residia na conscientização social. Em suas palavras, "o melhor guardião de um bem cultural é o seu dono" (MAGALHÃES, 1985, p.186).

Sob essa premissa, tentou-se criar o Programa de Recuperação e Revitalização de Núcleos Históricos (PRRNH) em cooperação com o Banco Nacional da Habitação (BNH). Porém, salvo a experiência pioneira e bem-sucedida de Olinda, o programa minguou com a extinção um ano depois do banco de fomento.

Nos anos 1990, durante o Governo Collor, as iniciativas federais de proteção do patrimônio chegaram ao fundo do poço. Foram extintos a SPHAN, seu Conselho Consultivo e a FNpM. O Instituto Brasileiro do Patrimônio Cultural (IBPC) ${ }^{13}$, que os substituiu, ficou reduzido ao corpo técnico estável do histórico SPHAN (BONDUKI, 2010, p.36).

Nesse contexto, abriu-se espaço para que os municípios - recém-alçados à posição de entes federativos independentes e autônomos pela Constituição Federal de 1988 - aderissem efetivamente à política pública de proteção do patrimônio cultural. Um trabalho pioneiro, que se ensaiava anos antes, foi a implementação pelo Município do Rio de Janeiro do Escritório Técnico do Corredor Cultural.

Nascido da delimitação de um amplo perímetro de proteção ao patrimônio da cidade, o Corredor Cultural visava a criar parâmetros que permitissem compatibilizar a recuperação, reforma ou construção de imóveis na área delimitada com a preservação arquitetônica e urbanística do centro histórico, na região de interesse cultural. O programa foi fundamental para o reconhecimento e valorização do patrimônio cultural da cidade e para sua reabilitação, sem que isso significasse o congelamento imobiliário (BONDUKI, 2010, p.36).

Já nas duas primeiras décadas do século XXI é que esse processo se consolidou, se não para todos os municípios brasileiros, ao menos para formar uma tendência geral. Nesse diapasão, a partir de proposta feita pelo Banco Interamericano de Desenvolvimento (BID $)^{14}$, o governo brasileiro vinha trabalhando na execução de um novo programa de recuperação dos centros históricos: o Programa Monumenta.

\footnotetext{
13 Em 1994, por meio da Medida Provisória no 610, de 08 de setembro, a instituição recém-nominada de IBPC retomou o nome IPHAN. Essa denominação e estrutura permanecem até a presente data.

14 O BID contava com uma experiência relativamente recente de reabilitação do centro histórico de Quito, depois do terremoto que atingiu a cidade em 1987.
} 
Em dezembro de 1999, foi assinado o empréstimo e, no ano seguinte, o Monumenta teve efetivo início, com a seleção dos municípios prioritários, sob supervisão técnica da UNESCO. A partir de um grupo de trabalho formado por especialistas e da definição de um ranking dos 101 núcleos históricos sob proteção federal, chegou-se a uma seleção de 26 municípios que seriam contemplados ${ }^{15}$.

Segundo Bonduki (2010, p.42), o modelo institucional proposto pelo Monumenta era baseado na descentralização, no controle social e na integração intergovernamental. Os municípios selecionados eram designados subexecutores do programa e tiveram que criar uma Unidades de Execução do Programa (UEP) setor responsável, em nível local, pela implementação do programa, com a atribuição de preparar, coordenar, supervisionar, executar e administrar financeiramente o projeto.

Em termos administrativos e financeiros, o Monumenta foi para os municípios aquilo que o PCH havia sido para os estados, notadamente para os estados nordestinos. Contudo, o desenvolvimento dos municípios como atores dessa política pública não foi homogêneo e o programa se desenvolveu de maneira mais ou menos eficiente de acordo com essa variável.

Nesse sentido, a partir de entrevistas com gestores, Giannecchini (2014, p.14) afirma que ficou evidente a necessidade de capacitação dos municípios, sendo muito grande o problema de pessoal. Os escritórios locais só funcionavam melhor onde o governo federal se envolvia mais. Essas questões tornaram tensa a relação com os municípios, uma vez que estes estavam pouco qualificados para o processo.

Segundo relatório divulgado pela Controladoria-Geral da União (CGU, 2015, p.47-48), até 2010, 37,54\% dos investimentos não haviam sido concluídos, sendo que 18,61\% sequer haviam sido iniciados. Assim, em dez anos de vigência do Monumenta, foram concluídos apenas $62,46 \%$ dos investimentos integrados programados. Além disso, da amostra definida para avaliação, 23,68\% dos investimentos integrados não se encontravam plenamente preservados, apresentando sinais de deterioração ou de ausência de manutenção.

Mesmo diante de resultados controversos, ante a proximidade do fim do Monumenta, o IPHAN - que em 2005 havia retomado seu protagonismo em detrimento do Ministério da Cultura (MinC) e do próprio BID - articulou-se politicamente para que o fosse mantido um programa de investimento no patrimônio cultural brasileiro.

Nesse contexto, em outubro de 2009, o então Presidente da República Luis Inácio Lula da Silva lançou, em Ouro Preto, o Programa de Aceleração do Crescimento das Cidades Históricas (PAC-CH), um braço do programa mais amplo de investimento público em obras de infraestrutura, o PAC. Em 20 de agosto de 2013,

\footnotetext{
15 São Paulo, Rio de Janeiro, Recife, Salvador, Ouro Preto, Olinda, Porto Alegre, Belém, Manaus, Mariana, Congonhas do Campo, Diamantina, Serro, Goiás, Natividade, Lençóis, Cachoeira, Laranjeiras, São Cristóvão, Alcântara, Corumbá, Penedo, São Francisco do Sul, Icó, Pelotas e Oeiras.
} 
a linha do programa para as cidades históricas foi novamente anunciada pela Presidente Dilma Rousseff, na cidade de São João Del Rei.

Apesar de nunca ter sido normatizado em lei ou decreto, o PAC-CH foi efetivamente implementado ainda em 2013, com um montante de investimento previsto na ordem de 1.639.620.000,00 (IPHAN, 2013). Esse valor adviria do orçamento geral da União, não mais do BID, e ficaria a cargo do IPHAN a execução direta ou o repasse da verba a outros entes federais. No que tange aos municípios, a transferência seria feita pela Caixa Econômica Federal (CEF), cabendo ao IPHAN atuar como órgão de fiscalização técnica.

Ao contrário do que se observou com o Programa Monumenta, em que os municípios adquiriram posição de destaque na política pública, o $\mathrm{PAC}-\mathrm{CH}$ até a presente data representou uma aparente recentralização das ações no órgão federal. Por exemplo, no Município do Rio de Janeiro, das 10 obras previstas, apenas duas ficaram a cargo da Prefeitura ${ }^{16}$, sendo que nenhuma dessas ultrapassou - passados seis anos desde o início do programa - a fase preparatória.

Segundo consta no site do IPHAN ${ }^{17}$, apenas 58 obras foram concluídas, totalizando um dispêndio de tãosomente $\mathrm{R} \$ 205.261 .487,21^{18}$ até $05 / 10 / 2018$, aproximadamente $12 \%$ do estimado. Com esses indicativos, ressalvado o fato de que o PAC-CH é um programa ainda em execução, por ora é possível argumentar que sua execução parece ir na contramão do que se observou no Monumenta, é dizer, indica uma recentralização da política pública de proteção do patrimônio cultural no âmbito federal, o que também não representou ganho de eficiência e eficácia.

\section{A cultura dos algoritmos}

Das concepções modernistas vigentes na fase heroica às premissas que orientam atualmente o PAC-CH, é inegável que a compreensão do significado de cultura - mais notadamente do conceito de patrimônio cultural - sofreu profundas mutações, mesmo sem nenhuma alteração normativa (textual) de grande escala.

Sendo uma política pública particularmente orientada por concepções fluidas, resultado de associações e dissociações de valores plurais, dinâmicos no tempo e espaço, compreender a participação dos diversos atores envolvidos em regra permite fazer projeções sobre as tendências de curto prazo a serem observadas.

\footnotetext{
${ }^{16}$ Requalificação do entorno do Passeio Público - Bairro Serrador e Restauração de Bicas e Chafarizes do Rio de Janeiro (Lagarto, Paulo Fernandes e Riachuelo). Dentre as demais, quatro foram direcionadas ao IPHAN, três ao Instituto Brasileiro de Museus (IBRAM) e uma à Fundação Biblioteca Nacional (FBN). As três últimas, por serem entidades autárquicas federais, recebem a verba através de termos de execução descentralizada firmados com o IPHAN.

17 Disponível em:

http://portal.iphan.gov.br/uploads/ckfinder/arquivos/PAC_cidades_historicas_obras_concluidas_05_10_2018.docx. Acesso em: 04 set. 2019.

18 Optou-se por excluir os valores referentes a três obras, ante a observação de que elas foram executadas com verba privada ou pública de outra fonte.
} 
Afinal, se cultura é um conceito relativo, a seleção do patrimônio que a representa simbolicamente e sua gestão é particularmente dependente da eleição - implícita ou explícita - dos critérios de decisão. E esse parâmetro jamais poderá ser excessivamente amplo, pois se tudo for considerado patrimônio cultural, nada o será. Em outras palavras, a constituição de um regime jurídico diferenciado sobre determinados bens materiais e imateriais pressupõe uma seleção desse distinto grupo.

Conforme visto acima, na fase heroica, esses critérios correspondiam à concepção da elite intelectual modernista daquilo que era cultura nacional. Em seguida, a aproximação do patrimônio cultural com o desenvolvimento econômico alterou significativamente os parâmetros de valoração e gestão. Os vários planos já referidos - PCH, PRRNH, Monumenta e PAC-CH - imbricaram-se diretamente com os critérios teóricos de seleção, influenciando-os e sendo influenciados numa complexa dinâmica de pensamento e ação.

Seguindo esse padrão, poder-se-ia apontar como perspectiva de um futuro próximo não mais uma descentralização vertical (União, estados e municípios), mas entre os poderes do mesmo ente federativo. Por exemplo, o poder judiciário, independente da esfera federativa, vêm buscando reconhecimento nos últimos anos como instituição mais próxima da população e, no que tange à política patrimonial, progressivamente substituindo o poder executivo (ERTHAL, 2017, p.229-235).

Entretanto, o futuro não é mais como era antigamente. No mundo das novas tecnologias, previsões ortodoxas - como a tendência de aumento do ativismo judicial - já nascem ultrapassadas. Nessa realidade contemporânea, projeções utópicas (ou distópicas) se tornam fato antes mesmo de entrarem no imaginário popular, e a política pública de proteção do patrimônio cultural certamente não seguirá imune a esse fenômeno.

Nessa esfera é que parece residir a próxima fronteira da política patrimonial. Nesses mais de 80 anos, os atores mudaram, os critérios de seleção mudaram, mas a lógica permaneceu idêntica. De forma mais centralizada ou descentralizada, com mais ou menos participação popular, o Estado sempre teve a palavra final para definir - especificamente nesse campo - o que é cultura. Talvez dentro de pouco tempo essa premissa já não seja verdadeira.

Com efeito, há cerca de 20 anos, o juiz norte-americano Frank Easterbrook (1996) causou silêncio constrangedor em um evento na Universidade de Chicago ao se referir ao direito das novas tecnologias (cyberlaw) como o "direito do cavalo" (law of the horse). Para Easterbrook, os juristas deveriam focar esforços em estudar e compreender contendas genéricas, cuja solução pudesse ser apreendida e replicada na prevenção e/ou resolução de outras similares.

Em resposta direta a essa provocação, Lawrence Lessig (1999b) publicou artigo no qual concordou com a premissa de que os estudos jurídicos deveriam conter certo grau de abstração, mas montou paradigmática 
teoria sustentando que o cyberlaw era muito mais abrangente do que Easterbrook havia proposto. Nas suas palavras:

\begin{abstract}
Concordo que nosso objetivo deve ser um curso que "ilumine todo o direito", mas, ao contrário de Easterbrook, acredito que exista um argumento geral importante que resulta do pensamento em particular sobre como a lei e o ciberespaço se conectam.

Este ponto geral é sobre os limites do direito como regulador e sobre as técnicas para escapar desses limites. Essa fuga, tanto no espaço real quanto no ciberespaço, vem do reconhecimento do conjunto de ferramentas que uma sociedade tem em mãos para afetar as restrições de comportamento. $O$ direito em seu sentido tradicional - uma ordem apoiada por uma ameaça direcionada ao comportamento primário - é apenas uma dessas ferramentas. O ponto geral é que o direito pode afetar essas outras ferramentas - que elas também restringem o comportamento e podem funcionar como ferramentas da lei. A escolha obviamente depende de sua eficácia. Mais importante, a escolha também levantará uma questão sobre valores. Ao trabalhar com esses exemplos de leis que interagem com o ciberespaço, evidenciaremos um conjunto de perguntas gerais sobre a regulamentação do direito fora do ciberespaço. (LESSIG, 1999b, p.502, tradução livre)
\end{abstract}

Para o bem ou para o mal, o futuro mostrou que Lessig havia acertado em seu diagnóstico e previsões. Hoje, a regulação do direito pela tecnologia e da tecnologia pelo direito se mostra muito mais generalizada do que na década de 1990 se pensava. E, para o que aqui interessa, a hipótese de que os critérios de seleção do patrimônio cultural brasileiro passarão por mudanças nessa direção não é remota, muito menos improvável.

Sobre o tema, Ted Striphas (2015, p.406) explica que cultura algorítmica representa a privatização do processo, isso é, da forma de tomada de decisão e contestação do conceito de cultura, compreendendo a luta contínua para determinar os valores, práticas e artefatos de grupos sociais específicos. A definição do autor é precisa e a utilização de algoritmos para seleção privada do patrimônio cultural já é uma realidade.

Nesse sentido, ao acessar o site Google Arts \& Culture, o usuário recebe uma série de indicações personalizadas pelo algoritmo do Google ${ }^{19}$. Para acessos no Brasil ${ }^{20}$, é provável a sugestão de um tour pelas obras de arte de Candido Portinari, intelectual modernista de grande influência na fase heroica, ou mesmo pelo Museu Nacional, edificação tombada destruída pelo incêndio de 2018.

Ao propor tais recomendações, o algoritmo do Google faz um processo de seleção dentre as tantas alternativas de conteúdo disponíveis. Essa escolha, porém, em muito difere daquela feita pelo Estado na execução da política patrimonial. Isso porque, ao contrário desta, a cultura do algoritmo é individualizada, pessoalizada, e não guarda relação necessária com o sentimento de pertencimento de um grupo social específico.

Nesse diapasão, é amplamente divulgado que plataformas como Google, Facebook e Amazon coletam dados e os utilizam para individualização de seus sites de acordo com o usuário. Analisando esse fenômeno,

\footnotetext{
19 Para uma análise dos principais argumentos éticos sobre os algoritmos, cf. MITTELSTADT, Brent; ALLO, Patrick; TADDEO, Mariarosaria; WACHTER, Sandra; e FLORIDI, Luciano. The Ethics of Algorithms: Mapping the Debate. Big Data \& Society, 2016.

${ }^{20}$ Acesso em: 05 set. 2019.
} 
Eli Pariser (2011) explica que os filtros de personalização criam em verdade uma bolha de conteúdo: o material consumido on line retroalimenta aquele indicado ao usuário, que se mantém inerte nesse círculo vicioso invisível.

Com isso, deixa-se de enxergar o desconhecido-desconhecido para ver apenas o desconhecidoconhecido (PARISER, 2011), ou seja, informações novas dentro daquilo que já era uma zona de interesse. O absolutamente novo é deixado de fora da bolha daquele usuário específico, criando-se assim um abismo cultural entre as pessoas. Dessa maneira, os algoritmos, ao individualizar excessivamente o conteúdo, podem até mesmo extinguir a noção de pertencimento a grupos sociais determinados, em sentido diretamente oposto à finalidade da proteção do patrimônio cultural brasileiro.

Por ora, não se tem notícia de conflitos relevantes envolvendo algoritmos e a execução da política pública patrimonial. As iniciavas privadas ainda não intervieram significativamente na atuação do Estado. Este, por sua vez, no que tange à política patrimonial, ainda limita sua atividade à regulação do mundo real, não do virtual.

Mas o que vai acontecer quando o Poder Público inserir no conceito de entorno de ambientação dos bens tombados também a realidade virtual ou aumentada? Com base no art. 18 do Decreto-lei nㅇ 25/193721, deveriam as empresas de tecnologia pedir autorização ao IPHAN para publicá-los? Nesse caso, como seria possível compatibilizar a celeridade de seleção dos anúncios pelos algoritmos com a burocracia estatal?

Nos exemplos citados acima (o tour pelas obras de Portinari ou pelo Museu Nacional), essas contendas se mostram mais próximas do que pode parecer. Mas elas também podem se dar em sentido contrário: imagine-se que o Poder Público determine o registro ${ }^{22}$ do algoritmo de recomendação da Amazon. Deveria a empresa divulgar o código para o governo brasileiro, ainda que com o compromisso de mantê-lo em sigilo?

Com efeito, a perspectiva que aqui se coloca é que, em algum momento próximo, esses dois mundos vão se encontrar. Tal como já aconteceu em outras áreas, a política patrimonial, ortodoxa e tipicamente estatal, deve em breve se deparar como mudanças determinadas pela cultura do algoritmo. Nesse tempo, retomar a contraposição de Lessig ao "direito do cavalo" pode ser de extrema valia para compreender que, na sociedade algorítmica, o direito nem sempre vai prevalecer sobre o código.

Também na esfera do patrimonial cultural, a regulação estatal parece estar cedendo espaço às outras formas: regulação social, pelo mercado ou pela arquitetura/código (LESSIG, 1999b, p.506-507). A seleção de

\footnotetext{
${ }^{21}$ Art. 18. Sem prévia autorização do Serviço do Patrimônio Histórico e Artístico Nacional, não se poderá, na vizinhança da coisa tombada, fazer construção que Ihe impeça ou reduza a visibílidade, nem nela colocar anúncios ou cartazes, sob pena de ser mandada destruir a obra ou retirar o objéto, impondo-se nêste caso a multa de cincoenta por cento do valor do mesmo objéto.

22 Registro é o instrumento de salvaguarda do patrimônio cultural imaterial instituído pelo Decreto no 3.551/2000.
} 
bens acautelados e sua gestão - marca determinante dessa política pública - passará pelo resultado dessa contraposição entre o antigo e o novo, entre o modernismo, o desenvolvimento econômico e a influência dos novos atores tecnológicos.

\section{CONCLUSÃO}

Conforme afirmado no início deste artigo, cultura é um termo de acepção ampla e, salvo se restrito em sua dimensão espacial e temporal, possui uma polissemia que dificulta sobremaneira sua conceituação. Entender a política pública de proteção do patrimônio cultural nas duas décadas do século XXI e as perspectivas futuras passa, necessariamente, pela investigação dos atores e premissas envolvidas no critério de seleção dos bens materiais e imateriais a serem acautelados.

Nessa esteira, as três primeiras décadas dessa atividade estatal (1937-1967) foram marcadas pelas concepções teóricas do movimento intelectual modernista, que ganhava espaço no Brasil desde a Semana de Arte Moderna de 1922. Prevalecia a noção de que o Poder Público deveria atuar para a construção de um patrimônio histórico e artístico tipicamente nacional, focado na arte erudita monumental e nos bens ligados a fatos memoráveis da história.

Com a aposentadoria de Rodrigo M. F. de Andrade, evidenciou-se a fragilidade institucional do órgão federal responsável pela execução dessa política pública. A partir de uma aproximação com a UNESCO, deuse início a uma fase de aproximação do patrimônio cultural ao desenvolvimento econômico, inicialmente através do turismo e em seguida com foco na comunidade.

Esse período foi caracterizado pela descentralização da política tanto dentro do governo federal (criação do PCH e do CNRC) como também para os estados-membro da federação. O valor histórico do tombamento passou a rivalizar em importância com o das belas artes, o que resultou em uma mudança de paradigma crucial para a compreensão atual da atuação estatal.

As duas décadas do século XXI, por sua vez, observaram uma ascensão dos municípios como co-atores junto à União e estados, notadamente ante o Programa Monumenta, financiado por empréstimo do BID. Já o PAC-CH aparentemente está representando uma relativa recentralização dessa competência junto ao IPHAN, mas esse diagnóstico demanda - eis que o programa ainda está em andamento - definitividade de dados e maior distanciamento temporal.

Por fim, tem-se como perspectiva para essa política pública uma potencial migração desse protagonismo para as grandes empresas de tecnologia, em especial com a difusão da cultura dos algoritmos. O futuro ainda é incerto, mas certo é que o direito normatizado e executado deverá se compatibilizar - não 
submeter, nem ser submetido - aos códigos. Por ora, esses conflitos são apenas potenciais, mas no mundo em que o futuro não é mais como era antigamente, o potencial se torna real em apenas um clique.

\section{REFERÊNCIAS}

ANDRADE, Mário de. A Capela de Santo Antônio. Revista do Patrimônio Histórico e Artístico Nacional, Rio de Janeiro, n.1, p.120125, 1937.

BONDUKI, Nabil. Intervenções urbanas na recuperação de centros históricos. Brasília: IPHAN, 2010.

CONTROLADORIA-GERAL DA UNIÃO. Relatório de avaliação da execução de programas de governo no 37: preservação do patrimônio histórico urbano. Brasília, 2015. Disponível em: https://auditoria.cgu.gov.br/download/3296.pdf. Acesso em: 04 set. 2019.

CUNHA FILHO, Francisco Humberto. Teoria dos direitos culturais: fundamentos e finalidades. São Paulo: Edições Sesc São Paulo, 2018.

DIOGO, Érika (Org.). Recuperação de Imóveis Privados em Centros Históricos. Brasília: IPHAN, 2009. Disponível em: http://portal.iphan.gov.br/uploads/publicacao/ColReg_RecuperacaolmoveisPrivadosCentrosHistoricos_m.pdf. Acesso em: 04 set. 2019.

EASTERBROOK, Frank H. Cyberspace and the Law of the Horse. University of Chicago Legal Forum, v. 207, p. 207-216, 1996.

ERTHAL, Thiago Serpa. A judicialização da política patrimonial no Estado do Rio de Janeiro. Publicações da Escola da AGU, Brasília, v.9, n.3, p.221-237, 2017

FONSECA, Maria Cecília Londres. O Patrimônio em Processo: trajetória da política federal de preservação no Brasil. 4. ed. Rio de Janeiro: UFRJ, 2017.

GIANNECCHINI, Ana Clara. O IPHAN e o Programa Monumenta: Lições para a gestão do patrimônio cultural. 2014. 25 f. Trabalho de Conclusão de Curso (Especialização)-Escola Nacional de Administração Pública, Brasília, 2014.

INSTITUTO DO PATRIMÔNIO HISTÓRICO E ARTÍSTICO NACIONAL. PAC Cidades Históricas: resumo por cidade/UF. 2013. Disponível em: http://portal.iphan.gov.br/uploads/ckfinder/arquivos/Investimentos\%20por\%20cidade.pdf. Acesso em: 04 set. 2019.

LESSIG, Lawrence. Code: and other laws of cyberspace. New York: Basic Books, 1999a.

LESSIG, Lawrence. The Law of the Horse: what cyberlaw might teach. Harvard Law Review, v. 113, p. 501-549, 1999 b.

LEFEBVRE, Henri. Le Droit à la ville. Paris: Anthropos. Coll. Société et urbanisme, 1968.

MAGALHÃES, Aloísio. E Triunfo?: a questão dos bens culturais no Brasil. Rio de Janeiro: Nova Fronteira, 1985.

MITTELSTADT, Brent; ALLO, Patrick; TADDEO, Mariarosaria; WACHTER, Sandra; e FLORIDI, Luciano. The Ethics of Algorithms: Mapping the Debate. Big Data \& Society, 2016.

PARENT, Michel. Proteção e valorização do patrimônio cultural brasileiro no âmbito do desenvolvimento turístico e econômico. 1968. In: LEAL, Claudia Feierabend Baeta (Org.). As Missões da UNESCO no Brasil: Michel Parent. Rio de Janeiro: IPHAN, 2008. Disponível em: http://portal.iphan.gov.br/uploads/publicacao/SerPesDoc3_MichelParent_m.pdf. Acesso em: 03 set. 2019.

PARISER, Eli. The Filter Bubble. Londres: Penguin, 2011.

SANT'ANNA, Marcia. Da cidade-monumento à cidade-documento. Salvador: Oiti Editora, 2014.

STRIPHAS, Ted. Algorithmic Culture. European Journal of Cultural Studies, v.18, p. 395-412, 2015. 